\title{
CIFOR Proposal Assessment Tool on Gender for Managers or Reviewers
}

This tool was developed for the Center for International Forestry Research but has broader relevance for all CGIAR Consortium members and their partners.
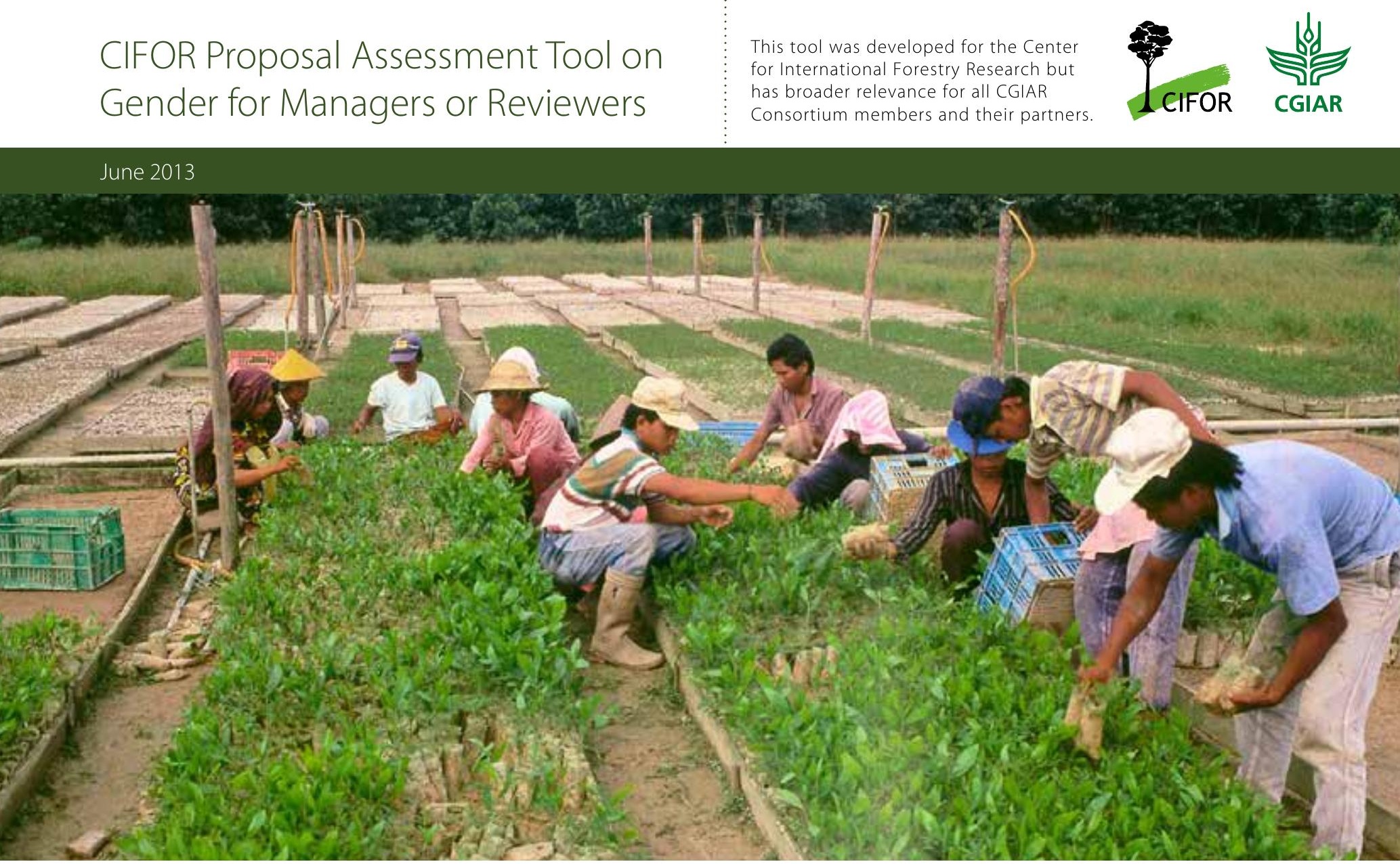

\section{Has this proposal demonstrated appropriate attention to gender issues?}

CIFOR scientists are now asked to actively consider whether and how gender is relevant to their research. Consequently, you must assess proposals for how well they communicate appropriate attention to gender issues. Gender integration in research is a fundamental part of doing good science, a means to help ensure that forestry research leads to equitable advances in human wellbeing and environmental conservation. This short guide will provide you with some key questions to consider as you review research proposals. It will also help you provide feedback to scientists and researchers on how they can strengthen attention to gender issues.

Gender-responsive research investigates the different priorities and needs of men and women. It also analyses how gender relations influence men's and women's ability to manage and use forests and forests products, as well as how policies affect men and women differently. Research aims to identify the underlying causes of gender inequalities. This involves collecting sex-disaggregated data and analysing gender inequalities to examine how these inequalities affect different groups of people. Gender-focused research is more likely to be conducted collaboratively with communities and other stakeholders to shape its scope and activities. Recommendations from this research will identify improvements for forest policies and practices that offer the best options for all parties and aim to address imbalances in assets or power.

\section{Goals and Objectives}

Researchers should consider how their goals and objectives explicitly contribute toward greater equity and poverty reduction consistent with CIFOR's purpose and with System Level Outcomes.

At a minimum, goals, objectives and outcomes can refer specifically to men and women, instead of just saying 'farmers' or 'community members'. However, they should strive to frame the goals, objectives and research questions to recognise gender as a key analytical and explanatory variable through which other social variables are examined. Not all projects can include a gender perspective.

Nonetheless, it is important to assess whether the proposal has tried hard to consider how the research can contribute to greater equity or apply gender analysis tools (Box 1).

- Has the proposal demonstrated how the research will be responsive to or will focus on gender issues? This can be demonstrated in the framing of the goals, objectives or research questions in the proposal. 


\section{Box 1. What if gender is not a relevant variable?}

Any scientific research that involves or affects humans should consider the different realities for women and men. Sometimes, however, social variables, including gender, are not important. If this is the case, the proposal should still explain why gender is not important to outcomes. It should also explain how the research contributes towards intermediate development outcomes and system-level outcomes to advance human welfare and environmental conservation.

Often it is not possible to determine whether gender is a significant variable before conducting analysis. Still, men and women are likely to experience a change as a result of the intervention. Thus, the proposal should demonstrate it has considered how to assess those changes and their potential impacts.

- Has the proposal included gender-specific research questions? Please consult the CIFOR resources listed in Box 2

\section{Beneficiaries}

If the research targets specific groups of beneficiaries, the proposal should demonstrate how it will integrate an analysis of gender and other socio-economic characteristics into the research. It should also demonstrate an understanding of how these variables may impact the participation of beneficiaries in the research or how they might benefit from activities.

- Has the proposal explained who the ultimate beneficiary/ies is/are? In describing the beneficiaries, the research can highlight key characteristics about the population including, sex, wealth status, ethnicity, age or religion.

- Has the proposal identified both men and women as beneficiaries?

- To what extent has the proposal described how it will ensure that both men and women are among the beneficiaries? The proposal should provide some indication that it considers how gender norms affect men's and women's participation in research activities, as well as how it plans to ensure they can have opportunities to benefit from activities.

- Does the proposal identify, as secondary beneficiaries, any women's groups or other organisations working in support of gender equality or women's rights?

\section{Activities}

\subsection{Data Collection and Analysis}

- Does the proposal describe what sex-disaggregated data will be collected? Since a gender analysis is about the relationship between women and men, it relies on relevant and valid data on both women and men, not simply on women or men alone. 


\section{Box 2. Looking for gender-related research questions?}

Consult the following resources:

- CIFOR. 2013. Gender in the CGIAR Research Programme on Forests, Trees, and Agroforestry: A Strategy for research and action. CIFOR, Bogor, Indonesia.

- Manfre, C. and Rubin, D. 2012. Integrating Gender into Forestry Research: A Guide for CIFOR Scientists and Programme Administrators. CIFOR, Bogor, Indonesia.

- CIFOR. 2011. CGIAR Research Programme 6: Forests, Trees, and Agroforestry: Livelihoods, Landscapes and Governance. Proposal. CIFOR, Bogor, Indonesia.

\section{Box 3. Pay attention to the gender composition of the team}

Advancing opportunities for women in science and research is an important goal for CIFOR and the CGIAR. Many donors, like the EU, are also increasingly paying attention not only to how gender is incorporated into the research content, but also how well institutions are supporting equal opportunities in their own policies and practices. Including women on the research team will not ensure the content of the research or its outcomes are more gender sensitive. However, promoting equal opportunities for men and women to participate in research is one step towards establishing a work culture that allows men and women to thrive.
- Is/are the method(s) appropriate for the scale of the research? If the research compares across countries, surveys may be more suitable. Participatory methods may be more useful in examining changes in access to rights to forests in a specific region.

- $\quad$ Are the method(s) appropriate for the target audience?

- Has the proposal demonstrated an understanding of the social context for the research, and designed an appropriate research process? For example, does it consider the need for men and women enumerators or interviewers? Depending on the cultural context, men should interview men and/or women should interview women.

- Does the proposal consider the need for mixed-and/or single-sex interviews, focus group discussions or other participatory activities?

\subsection{Partnerships and Alliances}

- Does the proposal include women's groups or other organisations working in support of gender equality or women's rights among its research partners?
Partnerships and alliances can be forged with such groups as regional or national gender committees, ministries of gender or women's affairs, or women's organisations and business associations.

- Does the proposal consider partnering with women's groups or other organisations working in support of gender equality or women's rights for advocacy and outreach?

\subsection{Knowledge sharing for policy and practice}

- To what extent does the proposal describe how it will document gender-disaggregated statistics, tables, figures, descriptions and analysis?

- To what extent does the proposal describe specific deliverables, publications or events to showcase genderrelated findings?

- Does the proposal include a plan for circulating findings to beneficiaries, including women? When it reports findings to communities, the proposal should ensure that women can understand and access the findings.

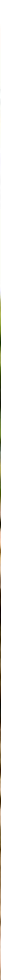


- $\quad$ To what extent does the proposal describe channels for sharing knowledge with women's groups, committees or other groups that support gender equality or women's rights?

\section{Capacity building}

- Does the proposal plan for gender training to ensure the research team has a common understanding of gender or other similar capacity-building efforts?

- Does the proposal include gender training for enumerators?

- $\quad$ Should the proposal include a workshop on tools or methods for gender analysis?

- $\quad$ Should the proposal consider identifying gender experts or organisations that could support the research team throughout the research process?

\section{Adaptive Learning}

- $\quad$ Are people-level indicators in the proposal disaggregated by sex?

- Has the proposal included sex-disaggregated indicators at the outcome level to measure changes in knowledge capacity or behaviours of target populations?

- Has the proposal included indicators to measure the key gender-related impacts noted in CGIAR Research Programme on Forests, Trees and Agroforestry? These include:

- $\quad$ Progress towards achieving gender equality in decision making and control over forest, trees and agroforestry resources and in increasing incomes and benefits for women through relevant value chains results;

- More women newly empowered to plant and manage forests, tree and agroforestry resources in programme countries;
- Less gender inequality in incomes from forest, tree and agroforestry goods and services;

- Better health conditions or less incidence of common illness from nutritional deficiency among women and their families;

- More women in elected/appointed leaders to forest management committees;

- More control (i.e., stronger rights) by women over forest, tree and agroforestry resources at household and community levels.

- Has the proposal included measurements to assess the effectiveness of the gender integration process? CIFOR is interested not only in capturing gender-differentiated outputs and outcomes, but also in discovering how well gender is being integrated into the research process. The proposal could include some indicators to measure progress towards improved capacity such as the number of trainings or improved knowledge of gender issues.

\section{Budget}

- Does the proposal set aside an appropriate level of funds to carry out gender-related activities - from data collection to knowledge sharing and dissemination? The budget may need to include costs associated with conducting intra-household surveys, separate focus groups for men and women or hiring a gender expert for the research team

- Does the proposal include any costs for capacity building?

- $\quad$ This might include resources for gender training to build capacity among the research team, enumerators and partners.

- Does the proposal allocate sufficient resources to monitor and evaluate impacts of research on both women and men beneficiaries?
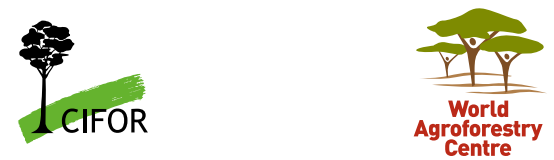

\section{cifor.org/forests-trees-agroforestry}

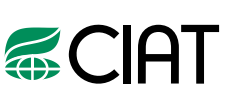
cirad
This research was carried out by CIFOR as part of the CGIAR Research Program on Forests, Trees and Agroforestry (CRP-FTA). This collaborative program aims to enhance the management and use of forests, agroforestry and tree genetic resources across the landscape from forests to farms. CIFOR leads CRP-FTA in partnership with Bioversity International, CIRAD, the International Center for Tropical Agriculture and the World Agroforestry Centre. 